\title{
Tratamento Da Informação No Nono Ano Do Ensino Fundamental: Uma Experiência A Partir Da Tabela Nutricional Do Biscoito Cream Cracker
}

\author{
Treatment Of Information In The Ninth Grade Of Elementary School: An Experience \\ From The Nutritional Table Of The Cream Cracker
}

\author{
Regiany Diorio da Conceição* \\ Secretaria de Educação do Espírito Santo - Sedu/ES \\ Lauro Chagas e Sá ${ }^{* *}$ \\ Instituto Federal do Espírito Santo - Ifes \\ Ícaro Chiabai*** \\ Instituto Federal do Espírito Santo - Ifes \\ Victor Augusto Giraldo ${ }^{* * * *}$
}

Universidade Federal do Rio de Janeiro - UFRJ

\begin{abstract}
Resumo
Diversas pesquisas no campo da Educação Matemática têm apontado que o ensino da Estatística e da Probabilidade contribui no desenvolvimento da capacidade crítica e da autonomia de indivíduos para que exerçam plenamente sua cidadania. Nesse contexto, apresentamos uma experiência de ensino, resultado parcial um projeto de pesquisa cujo objetivo é compreender as potencialidades da Educação Estatística para a compreensão de informações nutricionais, considerando o eixo da saúde como tema transversal para o Ensino Fundamental. O presente artigo, em especial, procura suscitar reflexões acerca de uma experiência com estudantes de nono ano de uma escola pública do Espírito Santo. Durante as seis aulas acompanhadas, no período de 01 a 14 de novembro de 2018, registramos observações do comportamento dos alunos, a interação entre os estudantes e os questionamentos suscitados. Além disso, as atividades desenvolvidas durante a sequência foram recolhidas para análise das resoluções de cada aluno. Ao final desta experiência, observamos que a atividade favoreceu a aprendizagem dos alunos em relação à Estatística, principalmente em função do tema em destaque. Por fim, concluímos que a realização dessa atividade possibilitou o amadurecimento dos estudantes, levando-os a pensar de forma crítica acerca da sua alimentação, principalmente no que toca o consumo de alimentos industrializados.
\end{abstract}

Palavras-chave: Educação Estatística, Tratamento da informação, Ensino Fundamental.

\footnotetext{
* Graduada em Estatística (UFES) e Especialista em Ensino de Matemática (UFES). Professora da SEDU. Serra, Espírito Santo, Brasil. E-mail: rddiorio@yahoo.com.br

** Doutorando em Ensino de Matemática (UFRJ). Professor do IFES e orientador do Curso de Especialização

“Matem@tica na pr@tica”(UFES).Vila Velha, Espírito Santo, Brasil. E-mail: lauro.sa@ifes.edu.br

*** Estudante do Curso Técnico em Biotecnologia Integrado ao Ensino Médio (IFES). Vila Velha, Espírito Santo, Brasil. E-mail: chiabaiicaro@gmail.com

**** Doutor em Engenharia de Sistemas e Computação (UFRJ). Professor do Instituto de Matemática da UFRJ.

Rio de Janeiro, Rio de Janeiro, Brasil. E-mail: victor.giraldo@gmail.com
} 


\begin{abstract}
Several researches in the field of Mathematics Education have pointed out that the teaching of Statistics and Probability contributes to the development of the critical capacity and the autonomy of individuals to fully exercise their citizenship. In this context, we present a teaching experience, as a partial result of a research project whose objective is to understand the potentialities of Statistical Education for the understanding of nutritional information, considering the health axis as a transversal theme for Elementary School. This article, in particular, seeks to elicit reflections about an experience with ninth grade students from a public school in Espírito Santo. During the six classes followed, from November 01 to 14,2018 , we recorded observations of students' behavior, the interaction between the students and the questions raised. In addition, the activities developed during the sequence were collected to analyze the resolutions of each student. At the end of this experiment, we observed that the activity favored students' learning in relation to Statistics, mainly in function of the theme in focus. Finally, we conclude that the accomplishment of this activity made possible the maturation of the students, causing them to think critically about their food, especially in what concerns the consumption of processed foods.
\end{abstract}

Keywords: Statistical Education, Information Processing, Elementary School.

\title{
1 Introdução
}

A relação entre o consumo de alimentos industrializados e o sobrepeso é observada há décadas pelos pesquisadores da área de saúde pública. De acordo com a Pesquisa Nacional por Amostras de Domicílios, realizada pelo Instituto Brasileiro de Geografia e Estatística (PNAD/IBGE), cerca de 82 milhões de pessoas têm seu Índice de Massa Corpórea (IMC) igual ou maior que 25, configurando sobrepeso ou obesidade (Abeso, 2015). Além disso, outro estudo desenvolvido a partir de dados do IBGE revelou que o consumo médio diário de sódio no Brasil é de 3,72g, sendo que a Organização Mundial de Saúde (OMS) recomenda que o consumo diário não exceda $2 \mathrm{~g}$, devido as complicações de saúde que esse excesso pode causar, como doenças cerebrovasculares (99.732 casos de morte em 2010) e infartos (79.668 casos em 2010).

Para modificar o panorama apresentado acima, a Agência Nacional de Vigilância Sanitária tem tomado uma série de medidas para conscientização da população acerca da composição dos alimentos industrializados. Por exemplo, a agência determinou, desde 2001, a apresentação obrigatória de informações nutricionais nos rótulos dos alimentos e bebidas (Anvisa, 2003; 2005). Nesse contexto, torna-se oportuna a realização de atividades de ensino que promovam a educação nutricional de brasileiros. Isto porque, com a tabela nutricional presente em alguns alimentos, e que procuramos problematizar em nosso estudo, podemos evitar o consumo exagerado e inconsequente. 
Esta pesquisa foi desenvolvida no âmbito de uma pós-graduação em Ensino de Matemática $^{1}$ e também está associada a um projeto financiado pelo Conselho Nacional de Desenvolvimento Científico e Tecnológico (CNPq) que visa compreender as potencialidades da Educação Estatística para a compreensão de dados nutricionais ${ }^{2}$. O presente artigo, em especial, tem como objetivo suscitar reflexões acerca de uma experiência de ensino que abordou a alimentação de estudantes de uma escola pública, tendo como base os resultados obtidos por meio das análises estatísticas. O texto a seguir inicia com um breve estudo teórico sobre Educação Estatística e Educação Alimentar. Na seção seguinte, serão descritos a escola-campo, o perfil da turma acompanhada, os momentos da intervenção e os instrumentos para produção de dados. Sequencialmente, traremos um relato reflexivo da experiência didática. Por fim, apresentaremos as conclusões e referências utilizadas neste estudo.

\section{Referencial Teórico}

A Matemática, enquanto ciência, é extremamente relevante para o desenvolvimento das diferentes áreas de conhecimento, bem como para solução de muitos problemas do dia-a-dia das pessoas. Entretanto, observamos em nossa experiência profissional que há uma crescente falta de interesse por parte dos alunos em relação a Matemática. Para superar essas dificuldades, Nascimento (2013) sugere que o professor organize materiais e atividades que sejam capazes de tornar o processo de ensino-aprendizagem mais atrativo, consolidando conhecimentos prévios e articulando o que o aluno já sabe com o que ele precisa saber. Com as tecnologias digitais disponíveis, também é possível que o professor leve para sala de aula recursos que auxiliem no processo de aprendizagem do aluno, como jogos matemáticos, resolução de exercícios por meio de softwares, pesquisa de campo, entre outros.

Entre os conteúdos que fazem parte do Currículo Básico da Educação, temos o tratamento da informação, que abre possibilidades para promover aprendizagens ainda mais interessantes, uma vez que a Estatística vem conquistando espaço na sociedade, como na tomada de decisões. Para Souza, Lopes e Souza (2015), o ensino de Estatística nas escolas desenvolve habilidades essenciais como a comunicação, resolução de problemas, tomadas de decisões. Também faz com que os estudantes possam agir como consumidores prudentes e

\footnotetext{
${ }^{1}$ Curso de Especialização "Matem@tica na pr@tica”, ofertado pela Secretaria de Educação à Distância da Universidade Federal do Espírito Santo.

2 Pesquisa desenvolvida no âmbito do EMEP - Grupo de Pesquisa em Educação Matemática e Educação Profissional (http://emep.ifes.edu.br) e cadastrada no Instituto Federal do Espírito Santo sob no PT00007193.
} 
responsáveis, além de auxiliar em outras questões no dia-a-dia do aluno. Além disso, observamos que o uso desse conceito nas aulas de Matemática atrai atenção dos estudantes, pelo fato de ser um conteúdo interessante e de desenvolver habilidades para coleta, organização e interpretação dos dados analisados.

De acordo com Lopes (2008), o ensino da Estatística e da Probabilidade na educação básica contribui no desenvolvimento da capacidade crítica e da autonomia de estudantes para que exerçam plenamente sua cidadania, ampliando suas possibilidades de êxito na vida pessoal e profissional, ou seja, permitindo que ele desenvolva habilidades essenciais, como análise crítica e argumentação. A pesquisadora afirma ainda que não basta ao cidadão entender as porcentagens expostas em índices estatísticos, como o crescimento populacional, taxas de inflação e desemprego. Para Lopes (2008), é preciso analisar criticamente os dados apresentados. Assim, como não é suficiente ao aluno desenvolver a capacidade de organizar e representar uma coleção de dados, faz-se necessário interpretar e comparar esses dados para tirar conclusões, conforme Guimarães (2013, p. 04) "é preciso conhecer sobre os dados, como interpretá-los, aprender a colocar perguntas críticas e refletidas acercado que é apresentado, ou seja, saber se os dados coletados são confiáveis e representativos da amostra".

Diante disso, o professor pode incentivar o protagonismo dos estudantes na busca da interpretação dos resultados obtidos por meio da Estatística, além de promover atividades diferenciadas utilizando não apenas dados fictícios.

De acordo com Castro e Castro Filho (2015), a escola precisa desenvolver atividades de busca e organização de dados para incentivar os estudantes a compreenderem as informações, representando na forma de tabelas e dados, contribuindo na formação dos alunos como cidadãos, além de desenvolver habilidades não apenas matemáticas, mas também o raciocínio lógico, a organização, o espírito investigativo e o senso crítico. Já segundo Bianchini, Bisognin e Soares (2015), trabalhar com a Estatística em sala de aula promove discussões e reflexões para solução de uma situação-problema, quer seja levantada pela classe ou instigada pelo professor, contribuindo para o desenvolvimento cognitivo.

Cazorla, Magina, Gitirana e Guimarães (2017) enfatizam que o trabalho com Estatística na escola propicia o desenvolvimento do pensamento estatístico ${ }^{3}$, a vivência de um trabalho interdisciplinar e possibilita abordar temas transversais, além de valorizar o mundo das

\footnotetext{
3 As autoras definem pensamento estatístico quando há tomadas de decisões, organização, intepretação e compreensão dos resultados obtidos.
} 
incertezas. Como já discutido anteriormente, o pensamento estatístico amplia as formas de pensar, valorizando o mundo das incertezas.

Como muitos autores enfatizam que o uso da Estatística permite o desenvolvimento intelectual e cognitivo dos alunos, acreditamos que trabalhar com dados relacionados à saúde na sala de aula pode contribuir com a conscientização acerca de uma boa alimentação. Isto porque uma das aplicações da Estatística são os estudos voltados para alimentação dos jovens, que, por sua vez, já evidenciam que adolescentes e crianças não possuem uma alimentação adequada (Silva, Teixeira \& Ferreira, 2014; Silva, Frazão, Osório \& Vasconcelos, 2015).

Conforme destacado por Alvarenga (2008), os padrões alimentares dos adolescentes costumam ser caóticos. Muitos desses pulam refeições principais, estabelecem associações distorcidas entre valores calóricos e nutritivos, além da frequência exorbitante em fastfoods. Nesse contexto, a orientação da alimentação na adolescência cria oportunidades de intervenção e medidas de educação em saúde, que poderão levar a hábitos saudáveis na vida adulta. Silva, Teixeira \& Ferreira (2014) e Silva et al (2015), reforçam ainda que as práticas educativas alimentares podem servir de meio para conscientizar crianças e adolescentes sobre como e por que se alimentarem de forma adequada, considerando que o ambiente escolar representa um espaço apropriado para a realização de práticas educativas alimentares.

De acordo com os Parâmetros Curriculares Nacionais - PCN (BRASIL, 1998), temas transversais, como a educação para a Saúde, cumprirão seus objetivos ao conscientizar os alunos para o direito à saúde, sensibilizá-los para a busca permanente da compreensão de seus determinantes e capacitá-los para a utilização de medidas práticas de promoção, proteção e recuperação da saúde ao seu alcance.

\section{Desenvolvimento E Percursos Metodológicos}

As aulas que apresentaremos a seguir ocorreram no período de 01 a 14 de novembro de 2018, em uma Escola Estadual localizada no município de Serra, região metropolitana da Grande Vitória, no Espírito Santo. A unidade de Ensino Estadual fazia parte do programa de educação em tempo integral, conhecido como Escola Viva ${ }^{4}$. Por isso, os alunos permaneciam de segunda à sexta-feira nos horários de 07h30min às $17 \mathrm{~h}$, com três intervalos durante o dia.

\footnotetext{
${ }^{4}$ O programa Escola Viva, implementado pelo governo estadual do Espirito Santo no ano 2015, é um programa das escolas estaduais de Ensino Fundamental e Médio em Turno Único, com foco em "transformar os jovens em autônomos e protagonistas da sua própria história”. Na ocasião da pesquisa, o programa possuía 36 unidades de ensino distribuídas em todo o Estado.
} 
$\mathrm{Na}$ época da pesquisa, a escola possuía 15 turmas, sendo 10 turmas do Ensino Fundamental e 05 turmas do Ensino Médio, totalizando 462 alunos matriculados.

Por fazer parte de um programa estadual de desenvolvimento da educação, a instituiçãocampo possuía diversos espaços físicos distribuídos em quatro pavimentos, sendo suas instalações prediais novas, além de oferecer recursos didáticos como televisão em todas as salas de aula, quatro retroprojetores e acesso à internet. Havia quatro laboratórios, sendo dois de informática com acesso à internet, um laboratório de Matemática e um de Ciências.

Ao todo, a escola contava com 26 professores, todos com carga horária de 40 horas semanais e, dentre esses professores, quatro possuem função de Professor Coordenador de Área (PCA). Estes, além de cumprirem uma carga horária em sala de aula, têm como função acompanhar e orientar os seus professores no planejamento, como também verificar o andamento do Guia de Aprendizagem nas reuniões semanais fixas, com sua equipe de área. $\mathrm{O}$ Guia de Aprendizagem, por sua vez, era um documento produzido trimestralmente por cada professor, no qual seriam informados o conteúdo a ser trabalhado semanalmente e as datas das avaliações, tendo como base o Currículo Básico do Estado do Espírito Santo.

A sequência de tarefas ocorreu numa turma do nono ano do Ensino Fundamental, composta por 35 alunos, com idade média de 14 anos. Era uma turma participativa composta por estudantes organizados e interessados. Apesar disso, alguns alunos eram agitados, indisciplinados, desinteressados e agressivos entre si. Quando realizam alguma atividade proposta, os estudantes da classe acompanhada, em sua maioria, pediam ajuda ao professor para esclarecimentos de dúvidas.

O tema da atividade foi Tratamento da Informação, focando no conjunto de dados relacionado com as informações nutricionais disponíveis nos rótulos dos produtos alimentícios. Foram abordados conceitos básicos, como distribuição de frequência em tabela e medidas de tendência central (média, mediana e moda). O plano de aula teve como principal objetivo capacitar os estudantes a desenvolver cálculos estatísticos de um determinado conjunto de dados. A realização das aulas totalizou cinco horas e meia e ocorreu em sala de aula e no laboratório de informática. A aditividade foi distribuída em seis aulas conforme quadro a seguir.

Quadro 01: Descrição sumária da atividade de ensino

\begin{tabular}{lll}
\hline Aula & Duração & Descrição \\
\hline Primeira aula & 30 minutos & Debate sobre informações nutricionais \\
\hline Segunda aula & 50 minutos & Pesquisa no laboratório de informática \\
\hline Terceira aula & 50 minutos & Definição do produto alimentício \\
\hline Quarta aula & 50 minutos & Revisão sobre média, moda e mediana \\
\hline Quinta aula & 50 minutos & Retornando com a revisão da mediana \\
\hline
\end{tabular}


Sexta aula 100 minutos Analisando o consumo médio do biscoito cream craker

Fonte: Elaborado pelos pesquisadores (2018).

Em todas as aulas foram feitas observações sobre seu desenvolvimento, com registros no diário de bordo. Ou seja, registramos observações do comportamento dos alunos como também de suas reações, a interação entre os estudantes e os questionamentos. Além disso, as atividades desenvolvidas durante a intervenção foram recolhidas para correção, como também para análise das resoluções de cada aluno.

\section{Reflexões Sobre A Experiência De Ensino}

Por conta de um evento escolar ocorrido no mesmo dia da intervenção, tivemos apenas trinta minutos para realização do primeiro momento da nossa atividade. A aula se iniciou com a apresentação do planejamento. Em seguida, a turma foi organizada em formato de círculo. $\mathrm{Na}$ lousa, foram descritas duas perguntas: Você possui conhecimento da tabela de informações nutricionais disponíveis nos rótulos dos produtos? Vocês sabem da importância dessas informações contidas nos rótulos dos produtos? Os estudantes responderam e puderam expor suas opiniões, no entanto, aproximadamente metade da turma relatou o desconhecimento dessas informações. Ao questioná-los sobre essas importâncias nutricionais, tivemos alguns discursos e desconhecimento, conforme as falas de alguns estudantes registrados.

"Não sabia que tinha isso" (Aluno AJDS)

"Não tinha conhecimento desse rótulo" (Aluno RST)

"Nunca me importei em olhar a embalagem do produto" (Aluno CKV)

Enquanto isso, outros alunos indicaram conhecimento sobre a tabela nutricional dos rótulos, mas a avaliaram como desinteressante, conforme algumas falas registradas:

"Tenho conhecimento dessas informações nos produtos, mas não dou muito atenção pra isso" (Aluno LLR)

"Não olho, principalmente se o produto for gostoso eu como tudo" (Aluno RAES)

"Eu sei da existência desses rótulos, mas não acho isso importante" (Aluno SMM)

"Já tinha visto, mas não sabia o que significava" (Aluno JVC)

"Acho desperdício essa informação" (Aluno ISC)

"Não olho, eu não tenho alergia, pra que ficar olhando" (Aluno KLS)

Ao observar o comportamento dos alunos durante essa aula, verificamos o desinteresse de alguns alunos com sua própria saúde, o que gera preocupações da forma como a tratam. Com isso, reafirmamos a importância de atividades de ensino em que são discutidos temas transversais como a saúde, os relacionando com o currículo base. Agindo assim, esperamos 
promover uma conscientização, levando os alunos à reflexão sobre o que é saúde, sensibilizando-os para uma melhor qualidade de vida, a partir de conteúdos aprendidos na escola (Brasil, 1998).

Na segunda aula, para que pudéssemos escolher o produto a ser trabalhado, realizamos uma pesquisa minuciosa no Laboratório de Informática, onde os alunos investigaram sobre as informações nutricionais contidas no rótulo e a sua importância. No entanto, apesar de compor um programa estadual de desenvolvimento da educação, o laboratório de informática não continha computadores suficientes para realização dessa pesquisa e não havia possibilidade de organizar os estudantes em dois grupos, sendo necessária a utilização dos computadores em dupla, o que gerou certo transtorno durante a aula.

Em seguida, realizamos a escolha do produto. Nesse momento, houve um tumulto natural, uma vez que os estudantes não entraram em consenso. De modo geral, a turma fícou dividida em grupos: alguns preferiram trabalhar as informações nutricionais de salgadinhos de milho; outros, de refrigerantes, de pizza, de balas de iogurte e até de sorvetes. Durante a aula da escolha do produto, um fator que chamou atenção foi os tipos dos produtos apontados pelos estudantes. Em nenhum momento houve citação de alimentos saudáveis, como frutas, mostrando que esses alunos não têm preocupações com sua própria alimentação. Os PCN definem temas transversais, como a saúde, e reafirmam a responsabilidade da escola na promoção de medidas práticas de saúde para conscientizar os alunos (Brasil, 2008). Por isso, aproveitamos esse momento discutimos a importância de uma boa alimentação em nossas vidas, os seus benefícios a curto e longo prazo.

Apesar de iniciarmos uma reflexão sobre a composição de todos esses alimentos, a aula terminou sem que fosse tomada uma decisão. Assim, foi solicitado aos alunos que realizassem a pesquisa em casa, verificando quais eram os alimentos mais consumidos por eles e pela sua família para compartilhar essa informação na aula seguinte.

Ao dar continuidade à atividade didática, logo no início da terceira aula, os estudantes informaram alguns alimentos para a escolha, de acordo com a pesquisa feita em casa. A turma, por fim, decidiu utilizar as informações do biscoito recheado. No entanto, após alguns questionamentos acerca do consumo desse produto, verificamos que seria inviável analisá-lo, pois alguns estudantes possuíam baixa renda e raramente tinham acesso a esse produto. Isto reforça a discussão que trouxemos na seção de referencial teórico, quando destacamos a importância da proximidade das informações à realidade dos alunos (Lopes, 2008; Souza, Lopes \& Souza, 2015). Outro aspecto importante na decisão de desistir desse produto foi o fato 
da maioria comer todo o pacote de biscoito recheado de uma única vez, o que diminuiria a variabilidade da amostra e dificultaria na aplicação dos cálculos estatísticos. Ao pontuar essas questões, os próprios alunos perceberam que seria inviável trabalhar com as informações nutricionais do biscoito recheado.

Considerando a realidade de alguns alunos, optamos por analisar a tabela nutricional do biscoito cream cracker. Esse produto foi escolhido tendo em vista que as famílias o consumem com frequência, por ser oferecido pela escola durante a merenda e também por ser consumido em porções, o que facilita o levantamento dos dados a serem analisados. O produto escolhido foi o biscoito salgado do tipo cream cracker, com 400 gramas e 70 unidades em cada pacote. Segue abaixo parte do seu rótulo contendo a informação nutricional.

\begin{tabular}{|c|c|c|}
\hline \multicolumn{3}{|c|}{$\begin{array}{l}\text { INFORMAÇÃO NUTRICIONAL } \\
\text { Porçẵo de } 30 \mathrm{~g} \text { (6 unidades) }\end{array}$} \\
\hline \multicolumn{2}{|c|}{ Quantidade por porção } & $\left.\% \mathrm{VD}()^{*}\right)$ \\
\hline Valor energetico & $135 \mathrm{kcal}=567 \mathrm{~kJ}$ & 7 \\
\hline Carboidratos & $22 g$ & 7 \\
\hline Proteínas & $3,0 \mathrm{~g}$ & 4 \\
\hline Gorduras Totais & $4,5 \mathrm{~g}$ & 8 \\
\hline Gorduras Saturadas & 1,50 & 7 \\
\hline Gorduras Trans & 1,20 & $*$ \\
\hline Fibra Alimentar & $0,7 \mathrm{~g}$ & 3 \\
\hline Cácio & $24 \mathrm{mg}$ & 2 \\
\hline Ferro & $1,1 \mathrm{mg}$ & 8 \\
\hline Sodio & $180 \mathrm{mg}$ & 8 \\
\hline $\begin{array}{l}\text { (") XV Vulones Diarios com } \\
\text { Seus valores diarios po } \\
\text { de sras necessidade }\end{array}$ & 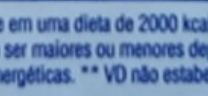 & 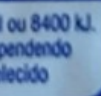 \\
\hline
\end{tabular}

Figura 1: Rótulo nutricional do biscoito cream cracker. Fonte: Acervo pessoal dos pesquisadores (2018).

Segundo a Agência Nacional de Vigilância Sanitária, a rotulagem nutricional se aplica a todos os alimentos e bebidas produzidos, com o objetivo principal de atuar em benefício do consumidor (Anvisa, 2003). Os cálculos para obter as medidas proporcionais de cada item da tabela nutricional de qualquer produto são realizados por meio de proporcionalidade, considerando como referência uma dieta diária de $2000 \mathrm{kcal}$ ou $8400 \mathrm{kj}$ de um indivíduo (Anvisa, 2005). De posse dessas informações, e com o produto escolhido, cada aluno anotou em seu caderno a quantidade média do consumo do produto industrializado em um determinado dia, conforme a figura abaixo. 


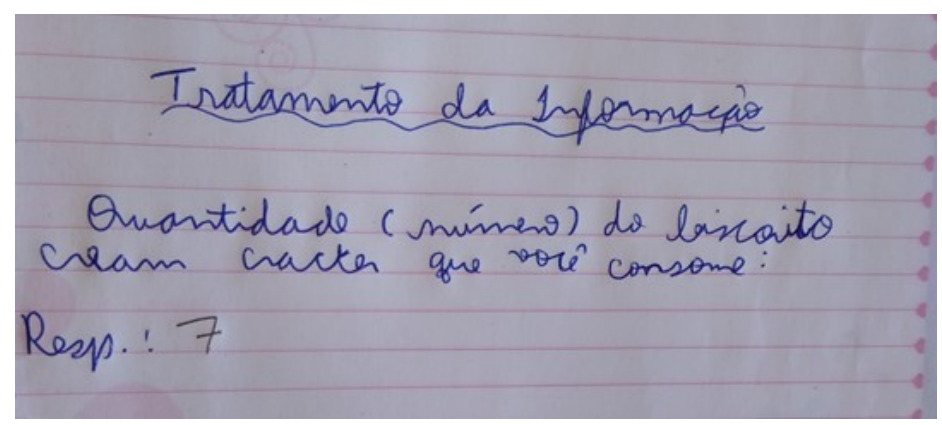

Figura 2: Descrição da quantidade do biscoito consumido por um aluno. Fonte: Acervo pessoal dos pesquisadores (2018).

Faltando vinte minutos para o encerramento da aula, iniciamos com os conceitos gerais de tratamento da informação, discutindo a formação da tabela de distribuição de frequência e também dos gráficos. Essa etapa da aula foi apenas uma retornada do conteúdo, uma vez que os alunos tiveram acesso no início do ano a esses conceitos, conforme descrito no guia de aprendizagem.

$\mathrm{Na}$ quarta aula, demos início aos estudos dos conceitos de medidas estatísticas de tendência central (média, moda e mediana). No que tange os dois primeiros conceitos, a maioria dos estudantes não teve dificuldades nos cálculos e compreensão do uso dessas medidas, como também sua aplicação. No caso da mediana, muitos alunos apresentaram dificuldades, principalmente em relação aos dois modos de obtenção dessa medida, considerando o número de elementos da amostra. Neste momento, foi necessário retornar à aula anterior, com a finalidade de consolidar o cálculo da mediana. Essas aulas foram trabalhadas com exercícios de diferentes contextos, com correção no quadro pelos próprios estudantes.

Na quinta e sexta aula da sequência, após consolidar os conceitos de Tratamento da Informação e realizar de alguns exercícios de revisão, iniciamos com análise estatística do consumo do produto biscoito cream craker. Cada estudante informou o número de biscoitos consumido, conforme solicitado anteriormente. Esta informação foi anotada pela professora no quadro. Em seguida, cada aluno recebeu uma lista de tarefas, que continha quatro atividades, sendo que a primeira consistia em preencher a tabela com as quantidades consumidas do biscoito cream cracker. 


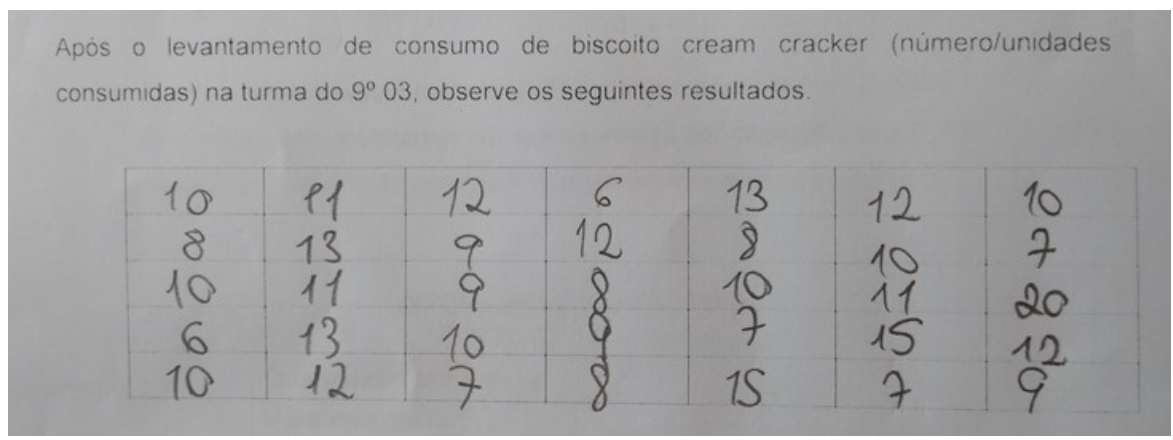

Figura 3: Conjuntos de dados brutos, relativo à quantidade de consumo de biscoito. Fonte: Acervo pessoal dos pesquisadores (2018).

Essa atividade tinha como objetivo de levar o aluno a compreender como as informações deverão ser organizadas em tabelas para futuramente serem analisadas, juntamente aos cálculos estatísticos, desenvolvendo habilidades e senso crítico, além de discutir os resultados a fim de buscar uma solução. Isto porque, conforme pontuado por Souza, Lopes e Souza (2015), o uso da Estatística nas aulas de Matemática permite que as pessoas ser tornem críticas e capazes de tomadas de decisões, como também agir como consumidores prudentes e responsáveis, além de auxiliar no dia a dia do aluno.

A segunda atividade foi referente a construção da tabela de frequência do consumo de biscoitos, apresentando os valores absolutos e os relativos à amostra, na forma de porcentagem. O momento foi tranquilo e nenhum aluno apresentou dificuldade.

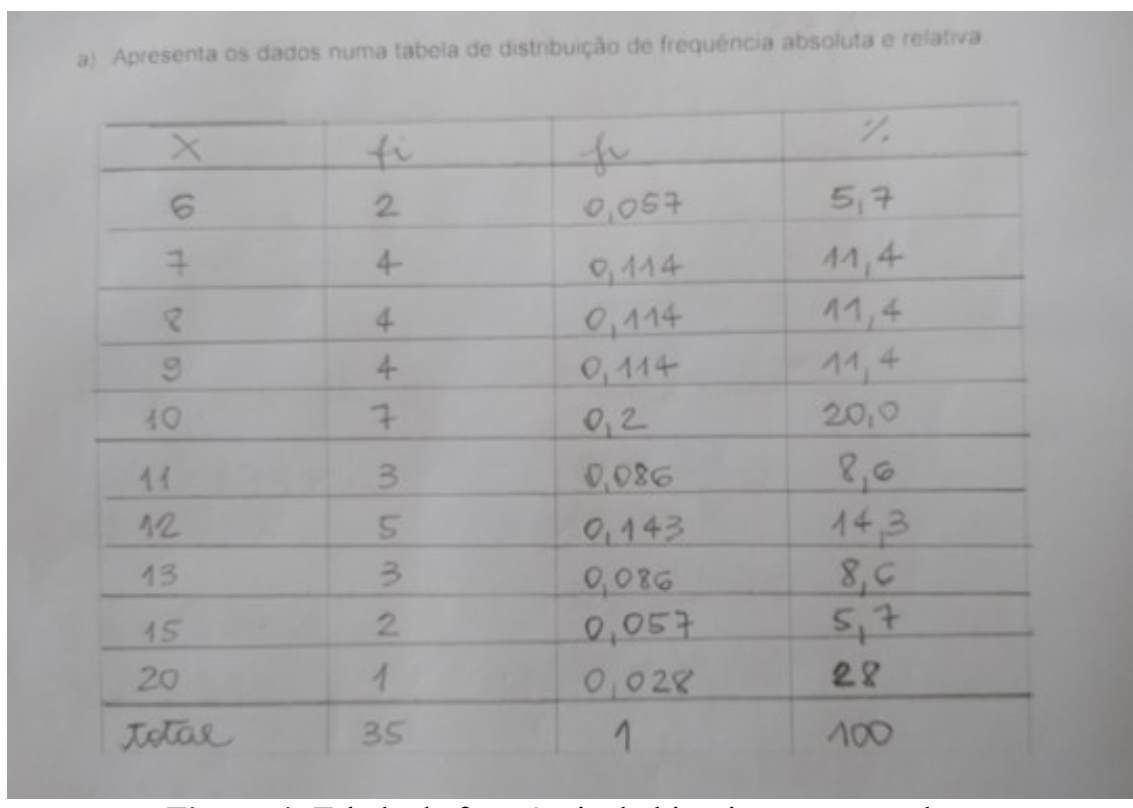

Figura 4: Tabela de frequência do biscoito cream cracker. Fonte: Acervo pessoal dos pesquisadores (2018).

Em seguida, procuramos determinar as medidas de tendência central da amostra. A moda foi determinada com certa facilidade pelos estudantes, visto que não depende diretamente 
de nenhuma operação aritmética. No caso da média, alguns alunos interpretaram a tabela de modo equivocado, ignorando a frequência em que os números foram apresentados. Também observamos dificuldade no cálculo da mediana, apesar da revisão realizada. Verificamos tais dificuldades em diferentes manifestações, como na resolução de um aluno, reproduzida abaixo.

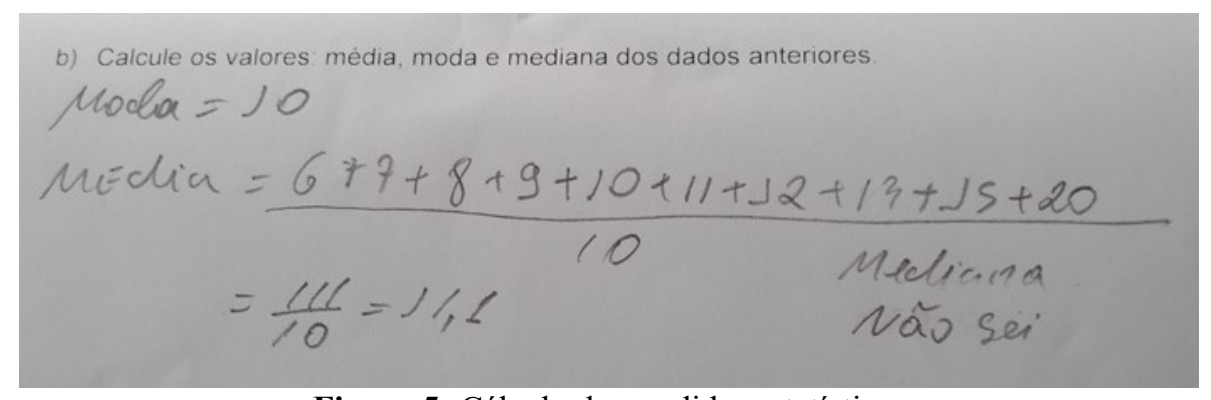

Figura 5: Cálculo das medidas estatísticas Fonte: Acervo pessoal dos pesquisadores (2018).

A maioria dos estudantes conseguiu chegar à solução sem dificuldades, com resoluções semelhantes à da figura 6 , feita por um aluno.

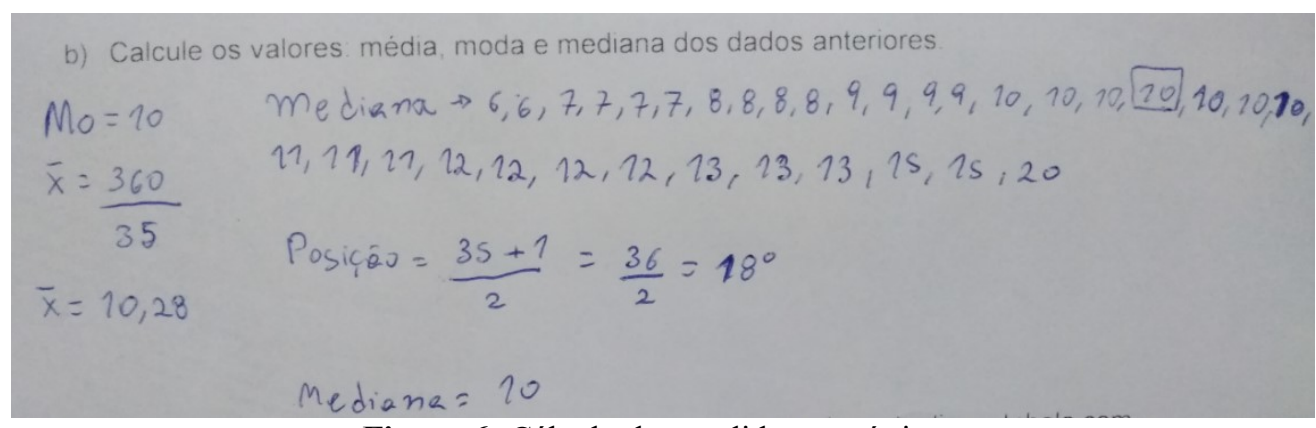

Figura 6: Cálculo das medidas estatísticas.

Fonte: Acervo pessoal dos pesquisadores (2018).

Depois de constituir a amostra, organizar os dados numa tabela de frequência e determinar as medidas de tendência central, a quarta atividade demandava que os alunos utilizassem a média de consumo de biscoitos da turma e refizessem a tabela nutricional do produto. Nesse momento, observamos que a maioria dos alunos utilizou do dispositivo da regra de três para chegar ao resultado proporcional, como pode ser visto na figura a seguir. 


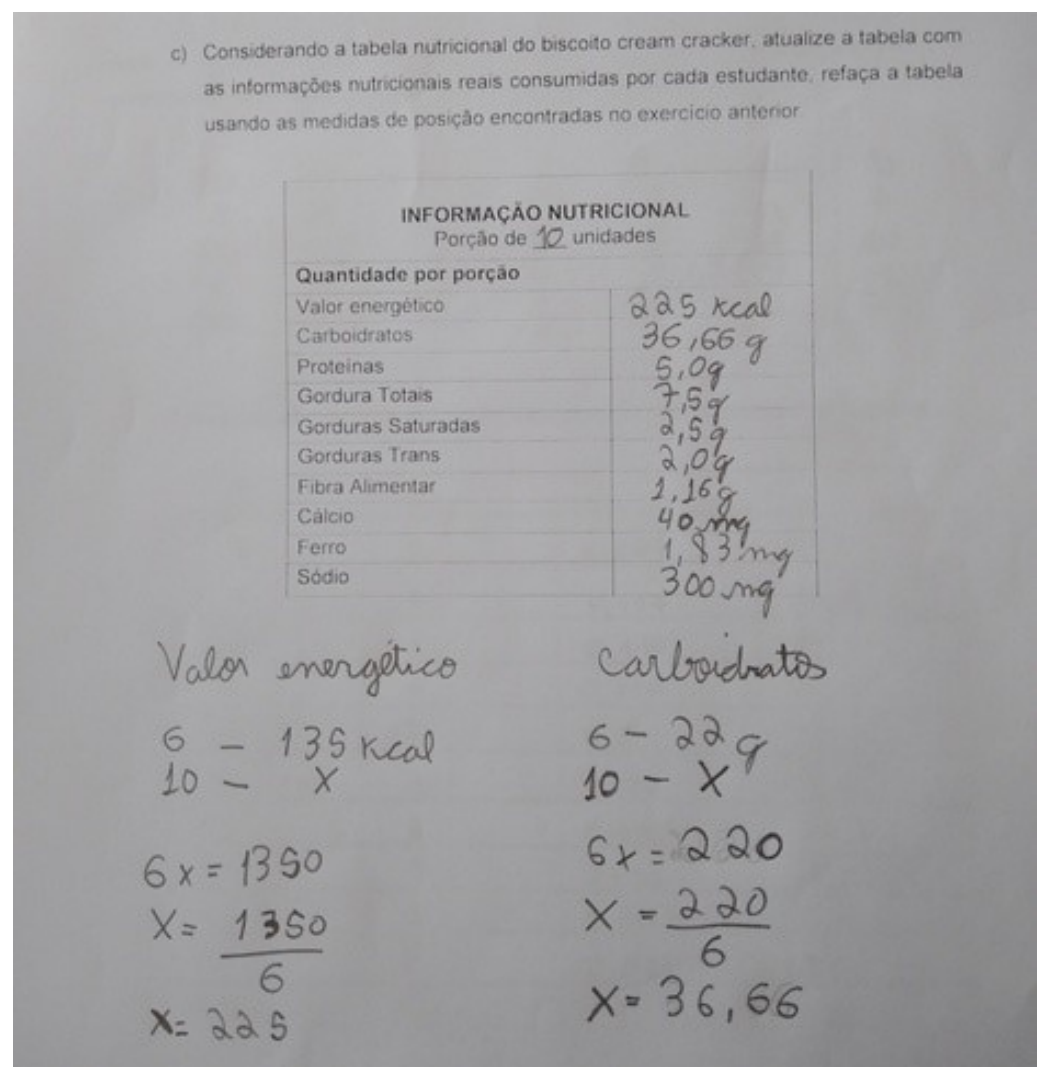

Figura 7: Rótulo nutricional do biscoito cream cracker reformulado Fonte: Acervo pessoal dos pesquisadores (2018).

Ao finalizar a tarefa, os alunos analisaram verbalmente os resultados encontrados, relatando que não imaginavam o valor correto do consumo de carboidratos e dos outros nutrientes. Na verdade, os estudantes reconheceram que acreditavam que os valores disponíveis nos rótulos pertenciam ao pacote inteiro. Ou seja, ao trabalhar com dados voltados para saúde nessa atividade didática, conforme destacado por Vasconcelos et al (2015), conscientizamos os estudantes acerca de uma boa prática alimentar. Ademais, foi possível que alguns alunos compreendessem essa importância ao ficar supresso com os resultados reais obtidos do consumo dos valores nutricionais.

Para esses estudantes, independente dos valores obtidos com os valores disponíveis nos rótulos nutricionais, o que interessava era satisfazer a sua vontade de comer. Aproveitando essa situação, debatemos conjuntamente os hábitos alimentares do dia a dia que poderiam causar prejuízos à saúde, como também a conscientização da alimentação adequada. Reforçando que o Souza et al. (2015) enfatiza, o uso de Estatística nessas aulas de Matemática permitiu uma interação entre os alunos no momento da resolução da lista de tarefa, um ajudando outro, como também na tomada de decisão ao escolher o produto industrializado, biscoito cream cracker, para análise Estatística. Corroborando ainda com as discussões de Lopes (2008), o uso desses índices estatísticos (moda, média e mediana) permitiu que o aluno tivesse o acesso na tomada 
de decisão por meio das interpretações e comparações dos dados dispostos nas tabelas de frequência e gráficos, como também na capacidade da organização desses dados.

\section{Considerações Finais}

A saúde e a alimentação são de extrema importância a todos cidadãos e estão fortemente relacionadas, apesar de muitos brasileiros não terem o hábito de ter uma alimentação saudável ou até mesmo de checar as informações nos rótulos nutricionais. Por meio desse estudo, acreditamos ter conscientizado os estudantes e estimulado o interesse sobre o que é consumindo e como esses nutrientes impactarão na saúde.

Trabalhar atividades cotidianas nas aulas de Estatística desperta o interesse dos alunos, conforme é destacado por diversos pesquisadores da área, como Lopes (2008). Na experiência de ensino em questão, a atividade favoreceu a aprendizagem dos alunos, principalmente em função do tema em destaque ser do interesse da maioria dos envolvidos. A maior dificuldade da implementação do planejamento da atividade didática foi o tempo corrido. A escola com sua agenda lotada de eventos culturais, o final do trimestre e o cumprimento do Guia de Aprendizagem impossibilitaram o desmembramento das aulas de Matemática para trabalhar com mais detalhes o conteúdo de Estatística. Provavelmente, se o tempo fosse mais propício, teríamos menos estudantes com dificuldades na resolução das atividades, além de podermos revisar proporcionalidade e regra de três com a turma, o que não foi possível nesse caso.

Ressalta-se que o momento mais desafiante da aula foi a determinação do valor nutricional consumido pela turma. Alguns estudantes acreditavam que o cálculo obtido não mudaria na qualidade da sua alimentação, enquanto outros estudantes demostraram surpresa com o resultado. De modo geral, os estudantes não tinham ideia da realidade do consumo nutricional que fazem cotidianamente e a realização dessas tarefas possibilitou o amadurecimento de cada um, levando-os a pensar de forma crítica acerca da sua alimentação.

A atividade em questão dá margem para um trabalho interdisciplinar com Ciências e Educação Física, no intuito de explorar um pouco mais questões relacionadas à alimentação e saúde, bem como a atividade física, mostrando uma possibilidade para futuros trabalhos tendo como base o trabalho que foi desenvolvido. A cada experiência de validação, aprimoramos as fichas de atividades relacionam educação nutricional e tratamento da informação, visando a interdisciplinaridade e promovendo o hábito alimentares de modo mais conscientes. Ao final 
do estudo, o material didático ficará disponível gratuitamente para download no site do EMEP - Grupo de Pesquisa em Educação Matemática e Educação Profissional ${ }^{5}$.

No projeto de pesquisa que circunscreve esta investigação, daremos continuidade à educação nutricional de alunos do Instituto Federal do Espírito Santo (Ifes), em turmas de primeiro ano do Curso Técnico em Biotecnologia integrado ao Ensino Médio, articulando formação básica e formação específica, na perspectiva do currículo integrado, considerando o campo de atuação dos profissionais egressos do curso. Pretendemos, ainda, questionar algumas manipulações realizadas nas tabelas nutricionais, como a diminuição da porção individual para tornar desprezível a porcentagem de nutrientes e atribuir ao produto o título de "livre de gorduras trans". Também é nosso objetivo, futuramente, problematizar o acesso às tabelas nutricionais pelos deficientes visuais, que não tem acesso à essas informações rotuladas. Em todo caso, esperamos que esta experiência de ensino tenha despertado o interesse de professores e pesquisadores para que também possam incluir em sua prática com Matemática ou Estatística aspectos relacionados à saúde.

\section{Agradecimentos}

Aos servidores e estudantes da escola-campo, por acreditarem nesta investigação e por viabilizarem seu desenvolvimento. Ao Conselho Nacional de Desenvolvimento Científico e Tecnológico $(\mathrm{CNPq})$ pelo financiamento da pesquisa.

\section{Referências}

Abeso - Associação Brasileira para o Estudo da Obesidade e da Síndrome Metabólica (2015). Quase $60 \%$ dos brasileiros estão acima do peso, revela IBGE. Recuperado de http://www.abeso.org.br/noticia/quase-60-dos-brasileiros-estao-acima-do-peso-revelapesquisa-do-ibge

Bianchini, D. F.; Bisognin, C. \& Soares, D. da S. (2015). Uma proposta didática para o ensino de estatística: o uso do Excel para representação gráfica. RENOTE - Revista Novas Tecnologias na Educação, 13 (02). Recuperado de https://seer.ufrgs.br/renote/article/view/61431

Brasil. Ministério da Educação. Secretaria de Educação Básica. (1998). Parâmetros Curriculares Nacionais (PCN). Terceiro e Quarto Ciclo do Ensino Fundamental.

\footnotetext{
${ }^{5}$ Disponível em http://emep.ifes.edu.br/index.php/11-producoes/25-materiais-didaticos
} 
Apresentação dos Temas Transversais. Secretária de Educação Fundamental. Brasília: MEC/SEF. Recuperado de http://portal.mec.gov.br/seb/arquivos/pdf/saude.pdf

Brasil. Ministério da Saúde. Agência Nacional de Vigilância Sanitária (Anvisa). (2003). Resolução Anvisa $n^{\circ} 360$. Estabelece o regulamento técnico sobre rotulagem nutricional de alimentos embalados. Recuperado de http://portal.anvisa.gov.br/documents/33880/2568070/res0360_23_12_2003.pdf/5d4fc71 $\underline{3-9 c 66-4512-b 3 c 1-a f e e 57 e 7 d 9 b c}$

Brasil. Ministério da Saúde. Agência Nacional de Vigilância Sanitária (Anvisa). (2005). Rotulagem Nutricional Obrigatória: Manual de orientação às indústrias de alimentos. Recuperado http://portal.anvisa.gov.br/documents/33916/389979/Rotulagem+Nutricional+Obrigat\%C 3\%B3ria+Manual $+\mathrm{de}+$ Orienta $\% \mathrm{C} 3 \% \mathrm{~A} 7 \% \mathrm{C} 3 \% \mathrm{~A} 3 \mathrm{o}+\% \mathrm{C} 3 \% \mathrm{~A} 0 \mathrm{~s}+\mathrm{Ind} \% \mathrm{C} 3 \% \mathrm{BAstrias}+\mathrm{de}$ + Alimentos/ae72b30a-07af-42e2-8b76-10ff96b64ca4

Castro, J. B. de \& Castro Filho, J. A. C. de (2015). Desenvolvimento do pensamento estatístico com suporte computacional. Educação Matemática em Pesquisa, 17 (5), 870-896. Recuperado de https://revistas.pucsp.br/index.php/emp/article/view/24999

Cazorla, I.; Magina, S.; Gitirana, V. \& Guimarães, G. (2017). Estatística para os Anos Iniciais do Ensino Fundamental. Brasília: Sociedade Brasileira de Educação Matemática - SBEM. Recuperado de http://www.sbem.com.br/files/ebook sbem.pdf

Guimarães, G. (2013). Estatística nos anos iniciais de escolarização. In K. S. Smole \& C. A. Muniz (Eds). A Matemática na sala de aula: reflexões e propostas para os anos iniciais do ensino fundamental, (pp.88-107). Edition: Penso.

Lopes, C. E. (2008). O Ensino da Estatística e da Probabilidade na Educação Básica e a Formação dos Professores. Caderno Cedes, Campinas, 28 (74), janeiro/abril, 57-73. Recuperado de http://www.scielo.br/pdf/ccedes/v28n74/v28n74a05.pdf

Nascimento, J. B. de S. (2013). O estudo da geometria espacial por meio da construção de sólidos com materiais alternativos. Lajeado. UNIVATES.

Silva, D. C. de A.; Frazão, I. da S.; Osório, M. M. \& Vasconcelos, M. G. L. de. (2015). Percepção de adolescentes sobre a prática de alimentação saudável. Ciência \& Saúde Coletiva, 20(11), 3299-3308. Recuperado de http://www.scielo.br/pdf/csc/v20n11/14138123-csc-20-11-3299.pdf

Silva, J. G.; Teixeira, M. L. O. \& Ferreira, M. A. (2014). Alimentação na adolescência e as relações com a saúde do Adolescente. Texto \& contexto Enfermagem, Florianópolis, 23 (4), 
1905-1103. Recuperado de http://www.scielo.br/pdf/tce/v23n4/pt_0104-0707-tce-23-0401095.pdf

Souza, L. O.; Lopes, C. E.; Souza, A. C. (2015). Os delineamentos metodológicos nas investigações brasileiras em Educação Estatística. Revista Perspectivas da Educação Matemática, 8 (número temático), 506-525. Recuperado de http://seer.ufms.br/index.php/pedmat/article/view/1461

Recebido em: 31/03/2019 Aceito em: 27/06/2019 